\title{
Assembly of pH-Responsive Antibody-Inspired \\ Protein-Drug Conjugates
}

Marco Raabe, ${ }^{\ddagger 1,2,3}$ Astrid Johanna Heck, ${ }^{\ddagger 1}$ Michaela Pieszka, ${ }^{1,2}$ Tao Wang, ${ }^{2,4}$ Maksymilian

Marek Zegota, ${ }^{1,2}$ Lutz Nuhn, ${ }^{1}$ David Y. W. Ng, ${ }^{1}$ Seah Ling Kuan, ${ }^{* 1,2}$ and Tanja Weil ${ }^{* 1,2}$

${ }^{1}$ Synthesis of Macromolecules, Max Planck Institute for Polymer Research, Ackermannweg 10, 55128 Mainz, Germany.

${ }^{2}$ Institute of Inorganic Chemistry I, Ulm University, Albert-Einstein-Allee 11, 89081 Ulm, Germany.

${ }^{3}$ Department of Synthetic Chemistry and Biological Chemistry, Graduate School of Engineering, Kyoto University, Katsura, Nishikyo-ku, Kyoto 615-8510, Japan.

${ }^{4}$ Institute of Urban Agriculture, Chinese Academy of Agricultural Sciences, Chengdu, 600213, P. R. China.

\section{KEYWORDS}

Protein-drug conjugate, antibody-inspired conjugate, dynamic covalent linker, avidin-biotin, boronic acid-salicylhydroxamate,

\section{ABSTRACT}

With the advent of chemical strategies that allow the design of smart bioconjugates, peptide- and protein-drug conjugates are emerging as highly efficient therapeutics to overcome limitations of 
conventional treatment, as exemplified by antibody-drug conjugates. While targeting peptides serve similar roles as antibodies to recognize overexpressed receptors on diseased cell surfaces, peptide-drug conjugates suffer from poor stability and bioavailability due to their low molecular weights. Through a combination of a supramolecular protein-based assembly platform and a $\mathrm{pH}-$ responsive dynamic covalent linker, we devise herein the convenient assembly of a trivalent protein-drug conjugate. The conjugate mimics key features of antibody-drug conjugates such as (1) a multipartite structure, (2) peptide recognition sites arranged at distinct locations and at defined distances, (3) a high molecular weight protein scaffold, and (4) an attached drug molecule. These antibody-inspired protein-drug conjugates target cancer cells that overexpress somatostatin receptors, enable controlled release in the microenvironment of cancer cells through an entirely new dynamic covalent biotin linker and exhibit stability in biological media.

\section{INTRODUCTION}

Biomolecules such as peptides and proteins are emerging as powerful therapeutics due to their ability to interact selectively with biological targets and to effect specific biological responses. ${ }^{[1]}$ One of the most eminent biotherapeutics are antibody-drug conjugate (ADC) that represent powerful treatment options by integrating the specific recognition of antibodies towards selective cell types with potent cytotoxic drugs that can induce apoptosis. ${ }^{[2]}$ In particular the recent progress in site-selective protein modifications expanded the chemical toolbox to design structurally precise ADCs with improved activities in a reproducible fashion. ${ }^{[3-7]}$ Moreover, the design of tailored linkers connecting the drug molecules with the antibody surface and allowing the controlled release of the drug payload stimulated by physiological environment unique to diseased cells has further increased their efficacy. ${ }^{[8,9]}$ Several ADCs are already in clinical trials, thus underlining 
their importance and potential in the market. ${ }^{[10-15]}$ Nevertheless, they still suffer from low penetration capacity to tumor microenvironment, immunogenicity and off-target toxicity. ${ }^{[16]}$ Furthermore, the production of antibodies is a lengthy process as they are usually isolated from animals, leading to elevated production costs. ${ }^{[16]}$ Targeting peptides, on the other hand, bind to a broad range of biological targets, exhibit low toxicity, and possess chemical diversity and high potency/selectivity. However, their application can be limited by short half-life and rapid clearance. ${ }^{[17,18]}$ To overcome the Achilles' heel, nanoparticles formulation with peptides have been devised but they are usually considerably larger, lack molecular precision and require biodegradability into non-toxic metabolites. ${ }^{[19]}$ In addition, we have previously established the assembly of multiprotein complexes that contain functional proteins as well as multiple copies of targeting peptides on an avidin to target cancer cells that overexpress somatostatin 2 receptors (SSTR2). ${ }^{[20-22]}$ The chemically engineered fusion protein have shown significant improvement for cell-type selective antitumor treatment compared to treatment with the antibody, avastin. ${ }^{\text {[20] }}$

Hence, the preparation of structurally defined antibody-inspired protein-drug conjugates combining multiple targeting groups as well as drug molecules connected by stimulus responsive linkers for controlled cargo release in the tumor microenvironment would offer several advantages. For instance, they could be optimized through synthetic chemistry to provide cell recognition and improved drug potency through the design of a stable linkage in blood circulation that can at the same time release the drug payload in the microenvironment at the tumor site. To fulfil the latter, there has been much interest to improve linker chemistry to control stability and release upon external stimuli. ${ }^{[9,23]}$ Dynamic covalent chemistry (DCvC) offers many attractive properties since it combines dynamicity of supramolecular chemistry, stability of covalent bonds, and is both reversible and stimuli responsive. ${ }^{[24-27]}$ The most classical example is the hydrazone linkage, 
which is often incorporated into delivery platform as a $\mathrm{pH}$-cleavable trigger but is non-reversible due to its slow association rate. ${ }^{[28,29]}$ Moreover, the slow reaction rate of hydrazine formation means that in situ generation of protein-drug conjugate is not feasible. Consequently, other $\mathrm{pH}$ responsive $\mathrm{DCv}$ linkers such as the dynamic $\mathrm{B}-\mathrm{O} / \mathrm{N}$ bonds with faster association rates have emerged. ${ }^{[27,30,31]}$ Recent findings have shown that the reactions of boronic acid derivatives with 1,2-diols or the salicylhydroxamic acid (SHA) offers advantages for protein conjugation, namely mild conditions, possibility of using water as a solvent, and $\mathrm{pH}$ responsiveness of the resultant $\mathrm{B}-$ $\mathrm{O}$ and $\mathrm{B}-\mathrm{N}$ bonds. ${ }^{[32,33]}$ The fast association rates of these interactions also allowed for rapid, insitu assembly of dynamic protein-drug conjugates. ${ }^{[34]}$ In addition, peroxide-triggered cleavage of the boronic acid can also induce release in cancer cells where high concentrations of hydrogen peroxide $\left(\mathrm{H}_{2} \mathrm{O}_{2}\right)$ is a hallmark of the tumor microenvironment. ${ }^{[35]}$

We report herein the design and rapid assembly of an antibody-inspired supramolecular proteindrug conjugate combining receptor-targeting somatostatin peptides and the drug doxorubicin (DOX) connected with a dynamic covalent adapter to mimics key features in ADCs such as (1) a multipartite structure exhibiting distinct function at each distinct site, (2) peptide recognition sides arranged at defined distances to mimic the two antigen-binding fragments (Fab) in antibodies that allows interactions with cell surface receptor in a multivalent fashion, (3) a high molecular weight protein scaffold, and (4) a cytotoxic drug molecule. These conjugates target cancer cells overexpressing somatostatin receptors for the controlled release of the cytotoxic drug in the acidic tumor microenvironment or under oxidative conditions and exhibit stability in biological media (Figure 1).

\section{RESULTS AND DISCUSSION}


Chemical Design and Synthesis. To prepare a stimuli-responsive trivalent protein-drug conjugate that possesses similar features to ADCs for targeted delivery, three components are required: (1) a dynamic covalent adapter to bridge the avidin carrier and cargo in a pH-reversible manner; (2) boronic acid modified drug or dyes as molecular cargo; and (3) the cyclic peptide, somatostatin, monofunctionalized with biotin to confer cell-type specificity to the conjugate (Figures 1).

To assemble and disassemble the cargo in a $\mathrm{pH}$ responsive fashion, we selected the dynamic interaction between boronic acid-salicyclhydroxamate (SHA). A bifunctional linker comprising of biotin and SHA was designed and synthesized. We started the synthesis of the biotin-SHA linker with a triethylene glycol chain, for both improved water solubility as well as sufficient spacer length to enable optimal binding to the biotin binding pocket and the boronic acid modified compounds. ${ }^{[36]}$ The overall synthesis route starting from compound $\mathbf{1}$ is depicted in the Supporting Information (Scheme S1). The syntheses of precursor compounds 1-7 were accomplished using previously reported protocols (Scheme S1) ${ }^{[37,38]}$ and the critical steps of the synthesis (compounds 8-11) are shown in Scheme 1A. All intermediate compounds were characterized by ${ }^{1} \mathrm{H}-\mathrm{NMR}$ and/or ${ }^{13}$ C-NMR (see SI). A trityl-protected ethynyl SHA (compound 9) ${ }^{[37]}$ was coupled to compound $\mathbf{8}$ by copper catalyzed azide-alkyne cycloaddition to afford compound $\mathbf{1 0}$ in quantitative yield. Compounds 9 and $\mathbf{1 0}$ were analyzed by liquid chromatography-mass spectrometry (LC-MS, see Figure S3-4) to determine their purity. The target compound 11 (biotin-SHA) was obtained through the deprotection of the trityl group under acidic conditions in quantitative yield. Compound 11 was characterized by ${ }^{1} \mathrm{H}-,{ }^{13} \mathrm{C}-\mathrm{NMR}$, COSY-45, and LC-MS (Figure S1-2 and Figure S5). Based on the COSY-45 measurement, all peaks in ${ }^{1} \mathrm{H}-\mathrm{NMR}$ could be assigned to the corresponding hydrogen atoms of biotin-SHA (Figure S1). The chromatogram of the LC-MS 
revealed at $214 \mathrm{~nm}$ and $254 \mathrm{~nm}$ only a single peak with $\mathrm{m} / \mathrm{z} 721[\mathrm{M}+\mathrm{H}]^{+}$and $743[\mathrm{M}+\mathrm{Na}]^{+}$, which is consistent with the calculated mass of compound 11 (calcd. mass: $721 \mathrm{~g} / \mathrm{mol}$, formula $\left.\mathrm{C}_{32} \mathrm{H}_{48} \mathrm{~N}_{8} \mathrm{O} 9 \mathrm{~S}\right)$.

In the next step, we synthesized boronic acid functionalized cargos, which can be bound to the SHA linker 11. To enable dynamic covalent binding of a drug to the SHA linker, we modified the chemotherapeutic doxorubicin (DOX), a known and marketed cytostatic, with a boronic acid group (compound 13) to yield DOX-B $(\mathrm{OH})_{2}$ (compound 14, see Scheme 1B). A carboxyphenylboronic acid (compound 12) was activated with $N$-hydroxysuccinimide (NHS) to form compound 13 and afterwards to react in a condensation reaction with the amine of DOX. Compound $\mathbf{1 4}$ was purified by HPLC (22\% yield) and further characterized by LC-MS. The chromatogram at $254 \mathrm{~nm}$ revealed a single peak and the masses: $\mathrm{m} / \mathrm{z}=690[\mathrm{M}-\mathrm{H}]^{-}, 714[\mathrm{M}+\mathrm{Na}]^{+}$(calc.: $691.21 \mathrm{~g} / \mathrm{mol}$ ) corresponding to compound 14 (Figure S6). Boronic acid modified dyes, namely BODIPY and rhodamine B were prepared as molecular cargoes. A NHS ester of the BODIPY (BDP, compound 15) dye was reacted with (4-(aminomethyl)phenyl)boronic acid (compound 16) to yield BDP$\mathrm{B}(\mathrm{OH})_{2}$ (compound 17, 44\% yield, see Scheme 1C). BDP-B $(\mathrm{OH})_{2}$ was characterized by ${ }^{1} \mathrm{H}-\mathrm{NMR}$ and LC-MS (Figure S7-8). The chromatogram at $254 \mathrm{~nm}$ revealed a single peak and the corresponding masses: $\mathrm{m} / \mathrm{z}=406.19[\mathrm{M}-\mathrm{HF}+\mathrm{H}]^{+}, 448.17[\mathrm{M}+\mathrm{Na}]^{+}, 489.21[\mathrm{M}+\mathrm{ACN}+\mathrm{Na}]^{+}$, $851.39[2 \mathrm{M}+\mathrm{H}]^{+}$, and $873.37[2 \mathrm{M}+\mathrm{Na}]^{+}$(Figure S8). Rhodamine dye was modified with a boronic acid group (Rho- $\left.\mathrm{B}(\mathrm{OH})_{2}\right)$ according to a previous protocol. ${ }^{[39]}$

For the targeting entity, we selected the cyclic peptide hormone somatostatin (SST), which binds to SST receptors overexpressed on cancer cells. ${ }^{[40,41]}$ SST consists of 14 amino acids and a single disulfide which allows incorporation of a single biotin (biotin-SST). ${ }^{[42]}$ Specifically, a bis-sulfonebased reagent was used and via subsequent Michael additions, disulfide rebridging was 
accomplished to introduce a single biotin functionality. ${ }^{[37]}$ The reagent was chosen as it was reported that the rebridging allows the site and receptor binding of SST to SSTR2 to be retained. ${ }^{[37]}$

Preparation of Somatostatin-Avidin Complex. The multidomain protein constructs were assembled using the avidin-biotin technology through a two-steps process. The components used for assembly include avidin, biotin-SHA, boronic acid modified cargos (BDP-B $(\mathrm{OH})_{2}$, DOX$\mathrm{B}(\mathrm{OH})_{2}$, Rho- $\left.\mathrm{B}(\mathrm{OH})_{2}\right)$, and biotin-SST (Figure 1). Avidin is a tetrameric protein of around 66 $\mathrm{kDa}$ in size and possesses four natural binding sites for biotin. We adopted a previously reported strategy for the assembly of different ratio of targeting peptides to avidin. ${ }^{[20]}$ First, a competitive binding assay using 2-(4-hydroxyphenylazo)benzoic acid (HABA) with lower binding affinity was used to achieve stoichiometric control (Figure 2A). Because of its higher affinity for avidin, biotin displaces HABA leading to a decrease of absorbance at $500 \mathrm{~nm}$ until complete disappearance upon saturation of all binding pockets (Figure 2B). In this way, avidin conjugates with different entities of SST (one (S1-Avi), two (S2-Avi) or three (S3-Avi) SST per avidin) were prepared following the reported method ${ }^{[20]}$ and the empty binding pockets were saturated with a biotin entity to investigate their binding on cell surfaces expressing SST2 receptors (SSTR2) (Figure 2C). Specifically, binding of these conjugates to the SSTR2 and whether this binding is promoted for conjugates with two or three SST per avidin, due to a possible multivalency effect, was studied for the first time herein using an agonistic calcium flux assay offered by Genscript. Serial dilutions of the three conjugates were added to wild type cells (CHO-K1/Ga15) and recombinant cells (CHOK1/Ga15/SSTR2) overexpressing SSTR2, respectively. The binding of S1-3-Avi conjugates was measured via a fluorimetric assay for calcium flux activation induced upon SSTR2 stimulation and the corresponding results are depicted in Figure 2C. While the wild type showed no binding of S1-3-Avi conjugates, the recombinant cells expressing SSTR2 revealed a concentration- 
dependent binding of S1-3-Avi conjugates and the $\mathrm{EC}_{50}$ values were calculated for each conjugate. As expected, a lower $\mathrm{EC}_{50}$ value was found for both S2-Avi $(137 \mathrm{nM})$ and S3-Avi (104 nM) conjugates compared to the S1-Avi (371 nM) conjugate (Table 1). Since S3-Avi has the lowest $\mathrm{EC}_{50}$ value, further investigations were performed using S3-Avi providing an additional empty binding site for the incorporation of a cargo.

Preparation of pH responsive S3-Avi-Cargo, Binding, and Stability Studies. Having determined the $\mathrm{EC}_{50}$ of $\mathrm{S} 3-\mathrm{Avi}$, we proceeded to determine the binding affinity of the Avi-SHA to boronic acid. The pH-dependent binding of Avi-SHA to boronic acid modified probes was investigated using fluorescence quenching, which is observed upon binding of boronic acid to AviSHA. ${ }^{[32,33]}$ Serial dilutions of S3-Avi-SHA starting at concentration of $250 \mu \mathrm{M}$ were titrated to a fixed concentration of $400 \mathrm{nM}$ BDP-B $(\mathrm{OH})_{2}$ at $\mathrm{pH} 7.4$ or $\mathrm{pH} 6$ and incubated for 30 minutes (Figure 3A). A plot was obtained from the change in fluorescence intensity induced by the binding of Avi-SHA to BDP-B $(\mathrm{OH})_{2}$ and the $\mathrm{K}_{\mathrm{d}}$ was determined to be $2.4 \pm 0.74 \mu \mathrm{M}$ for Avi-BDP (Figure 3B). The result is consistent with previous findings where the SHA-boronic acid interactions are in the low $\mu \mathrm{M}$ range ${ }^{[43,44]}$ As expected, there was no binding under acidic conditions showing the $\mathrm{pH}$-dependence of the system, which is attractive for the release of molecular cargoes in acidic endolysozomes of cancer cells or in acidic cancer microenvironment. Next, we proceeded to prepare various $\mathrm{pH}$-responsive $\mathrm{S} 3$-Avi-Cargo assemblies $(\mathrm{Cargo}=\mathrm{Dox}, \mathrm{BDP}$, and Rho $)$. Based on the stoichiometric optimization using HABA, biotin-SHA was added to S3-Avi in the ratio of 1:1 (Figure 2B). The resultant S3-Avi-SHA complex was then incubated with the boronic acidmodified cargo molecules modified with boronic acid (Figure 3A) to form three different S3-AviCargo complexes. The resultant complexes were purified by ultrafiltration at a MWCO of $10 \mathrm{kDa}$ and characterized by UV-VIS (Figure 3C). The identity of the S3-Avi-Cargo was confirmed by 
the emergence of the characteristic absorbance peak of the respective cargoes (Figure 3C, $\lambda_{\mathrm{BDP}}=$ $509 \mathrm{~nm} ; \lambda_{\text {DOX }}=480 \mathrm{~nm}$ ). The binding of S3-Avi-SHA to the boronic acid modified cargoes was further confirmed by Förster resonance energy transfer (FRET), where energy transfer can only occur between two fluorescent entities in close proximity $(>10 \mathrm{~nm}){ }^{[45]}$ We selected Cy5 and rhodamine as FRET pair where rhodamine acts as donor and Cy5 as acceptor. For FRET measurements, we statistically labeled Avi with Cy5. Cy5 labeled S3-Avi-SHA and Rho-B(OH $)_{2}$ were mixed in a ratio of 1:1 and were incubated for 20 minutes to form S3-Avi-Rho. Cy5-labeled S3-Avi-SHA was implemented as a negative control. Upon excitation at a wavelength of $540 \mathrm{~nm}$ we measured the emission of Cy5 at $672 \mathrm{~nm}$, a significant increase in the emission signal of Cy5labeled S3-Avi-Rho at $672 \mathrm{~nm}$ was observed compared to the control S3-Avi-SHA (Figure 3D), suggesting the occurrence of an energy transfer. This confirmed the successful binding of Rho$\mathrm{B}(\mathrm{OH})_{2}$ to S3-Avi-SHA (Full emission spectra are depicted in Figure S9).

Somatostatin has a short half-life ( $<3$ minutes) and this often hampers its application. ${ }^{[46,47]}$ Thus, we further investigated the stability of the supramolecular construct, S3-Avi-BDP $(100 \mu \mathrm{M})$, in $10 \%$ fetal calf serum. Aliquots were drawn after incubation of 2, 6, 12, and $24 \mathrm{~h}$ and directly applied and analyzed using size exclusion chromatography on a fast protein liquid chromatography (FPLC) system with a multiwavelength detector. Remarkably, the construct remained intact up to $24 \mathrm{~h}$, confirming its stability. Since boronic acid is known to undergo oxidative cleavage to form phenols ${ }^{[48]}$ we further tested the cleavage of the cargo and its release under biologically relevant concentration of hydrogen peroxide $(5 \mu \mathrm{M})^{[49]}$ using FPLC (Figure 3E). At $2 \mathrm{~h}$, there was already a significant decrease in the signal by about $59 \%$ at $\lambda=480 \mathrm{~nm}$, indicating the dissociation of S3Avi-BDP into S3-Avi and free BDP. After 24 h, up to $91 \%$ of the S3-Av-BDP had dissociated, 
suggesting that besides $\mathrm{pH}$, controlled release of the cargo can also be achieved under oxidative conditions found inside cancer cells with neutral extracellular microenvironment. ${ }^{[50]}$

Cellular Uptake and Cytotoxicity Studies. SST is an endogenous peptide hormone released through a variety of stimuli and is binding to the membrane's GPCR receptors SSTR1-5. Many solid tumor cell lines, including human lung cancer cell line A549, are overexpressing SSTR2 receptors, and thus SST has been used for tumor diagnostics and therapeutic purposes. We first determined that SSTR2 are expressed in A549 cells using Western Blot (Figure S10). Since receptor-mediated uptake is an energy-dependent process, ${ }^{[51]}$ the cell uptake of S3-Avi at $4{ }^{\circ} \mathrm{C}$ and $37{ }^{\circ} \mathrm{C}$ into the SSTR2-expressing A549 were quantified using flow cytometry. At $4{ }^{\circ} \mathrm{C}$, cell internalization was quenched in both $200 \mathrm{nM}$ of S3-Avi and Avi (control) after 30 minutes of incubation (Figure 4A) but could get more pronounced at $37^{\circ} \mathrm{C}$. After $4 \mathrm{~h}$ incubation at $37^{\circ} \mathrm{C}$, the preferred uptake of S3-Avi over the control Avi became more significant compared to 30 minutes incubation (Figure S12). Taken together, our results suggest that the internalization of S3-Avi is mostly guided by a receptor-mediated uptake rather than passive diffusion.

The translocation of a molecular cargo by S3-Avi into A549 cells was confirmed by confocal microscopy using Cy5 labeled S3-Avi-BDP. Incubation of S3-Avi-BDP (500 nM) for $4 \mathrm{~h}$ already showed efficient uptake into A549 using confocal microscopy (Figure 4B). Considering the possible intracellular release of the cargo from the conjugate, cytotoxicity of a boronic acid modified model drug DOX (DOX-B $\left.(\mathrm{OH})_{2}\right)$ was investigated. The cytotoxicity and $\mathrm{IC}_{50}$ of S3-AviDOX towards A549 were determined after incubation for $24 \mathrm{~h}$. S3-Avi-DOX $\left(\mathrm{IC}_{50}=5.42 \mu \mathrm{M}\right)$ significantly reduced cell viability compared to $\mathrm{DOX}\left(\mathrm{IC}_{50}=37.36 \mu \mathrm{M}\right)$ treatment alone (Figure 4C). The enhancement of $\mathrm{IC}_{50}$ of S3-Avi-DOX compared to free DOX is presumably due to more efficient uptake and release from the S3-Avi platform. 


\section{CONCLUSION}

In summary, we present a stable, trivalent protein-drug conjugate based on an avidin adaptor platform, which mimics key features in antibody-drug conjugates: (1) cell targeting entity, (2) bioactive cargo, and (3) stable yet reversible linker. In addition, the dynamic covalent linker allows facile exchange of cargoes on demand. The conjugate is taken up by cancer cells expressing SSTR2 and exhibit stability in biological media. In addition, the reversible assembly of the conjugates using dynamic covalent interactions of boronic acid with salicylhydroxamates enabled controlled cargo release in response to $\mathrm{pH}$ or oxidative agents and demonstrated enhanced cytotoxicity of the drug DOX which are transported into SSTR2 receptor overexpressing cell lines. The platform and chemical strategy presented herein allows the rapid generation of a library of smart, antibodyinspired protein-drug conjugates and overcome the inherent stability issues with peptides. We envisage that the reported technology will open new avenues for the innovation of "on-site" conjugation of smart "antibody-inspired" protein-drug conjugates that respond to various stimuli found inside tumor cells and expands the current repertoire of protein therapeutics beyond classical ADCs. 


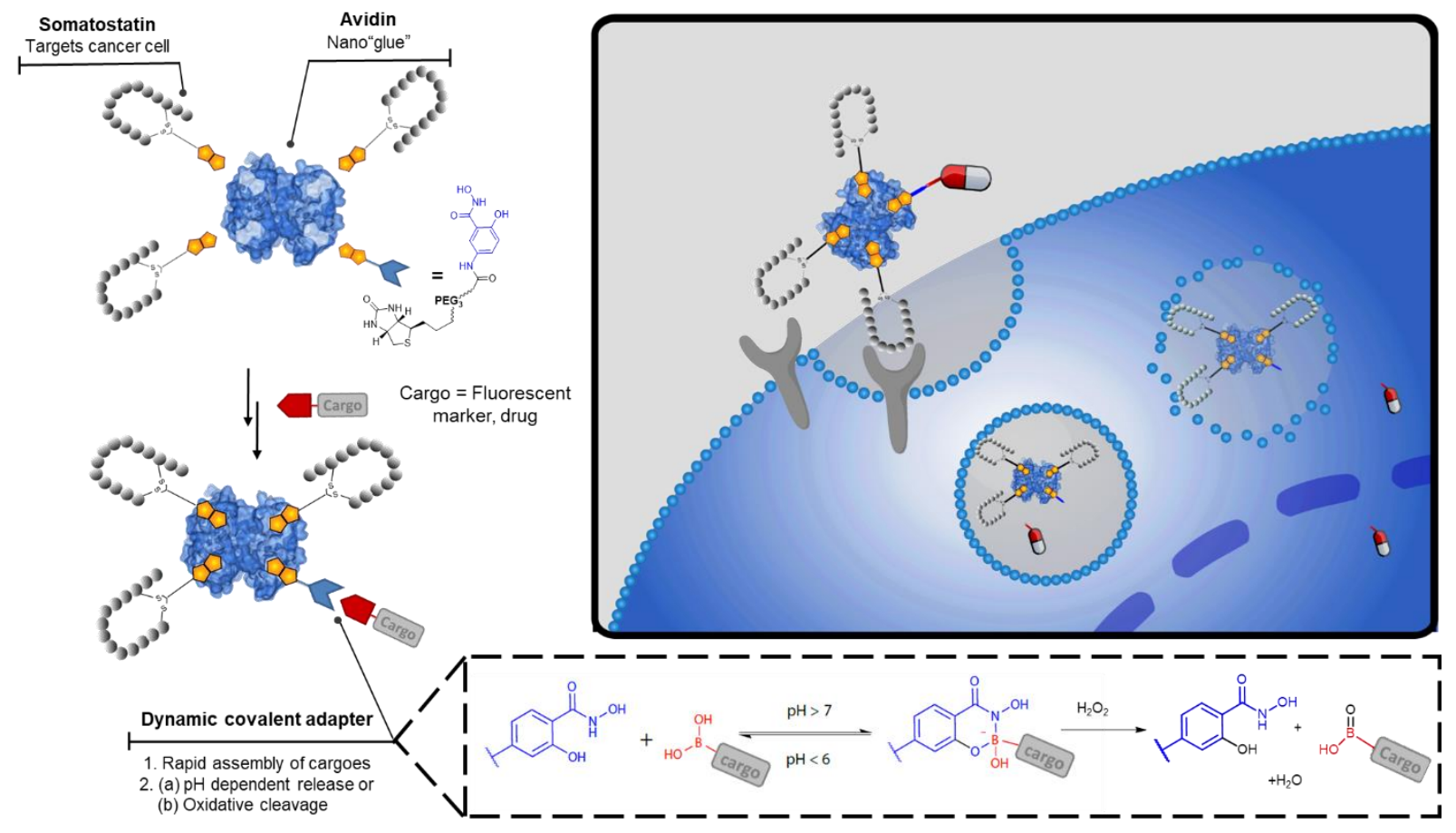

Figure 1: Illustration of the design of an antibody-inspired protein-drug conjugate that can (1) address receptors overexpressed on cancer cells in a multivalent fashion to achieve internalization and (2) controlled release of molecular via $\mathrm{pH}$ or oxidative cleavage of a dynamic covalent linker. 
A

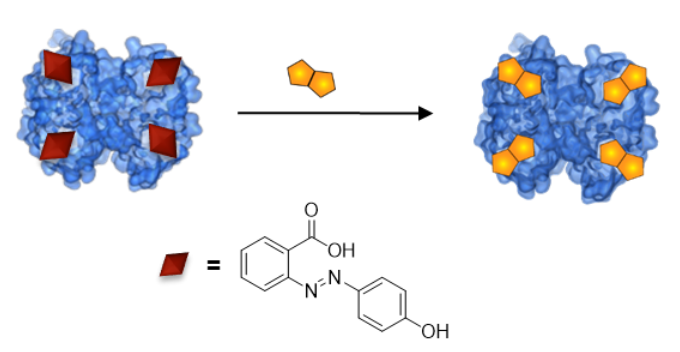

2-(4-hydroxyphenylazo)benzoic acid (HABA)

C
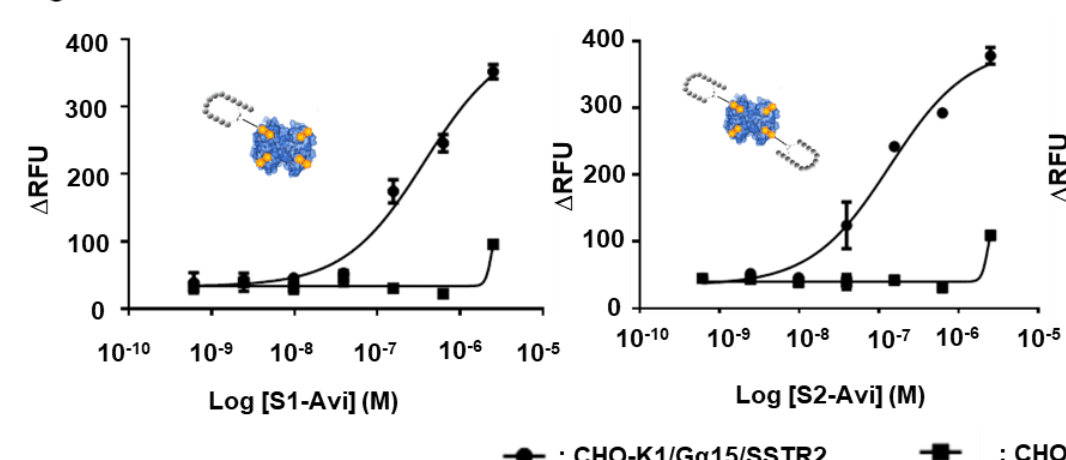

: CHO-K1/Ga15/SSTR2
B

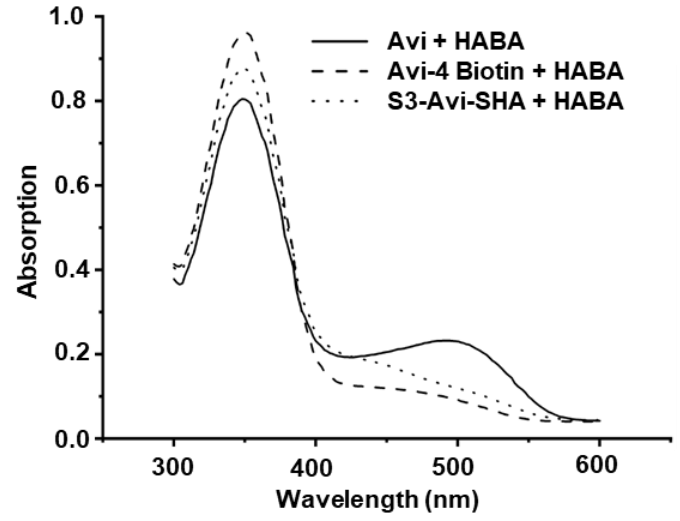

Figure 2. (A) Schematic illustration of competitive binding of HABA and biotin to avidin. (B) HABA binding assay of Avi, Avi saturated with biotin, and S3-Avi-SHA. (C) Calcium flux assay (Genscript) to measure calcium release induced by the agonistic interactions between SSTR2 and S1-S3-Avi with CHO-K1 cells overexpressing SSTR2 (circles) and wild type CHO$\mathrm{K} 1$ cells (squares). $\mathrm{RFU}=$ relative fluorescence units. 
A

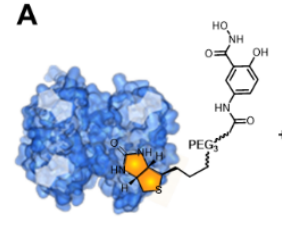

Avi-SHA

C
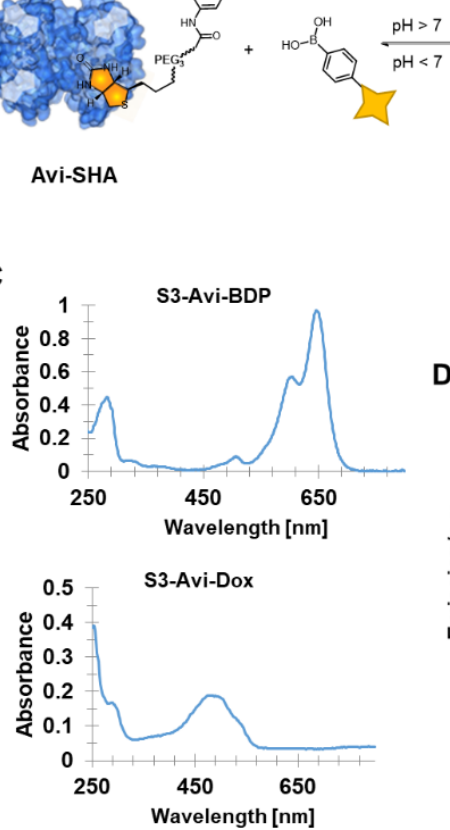

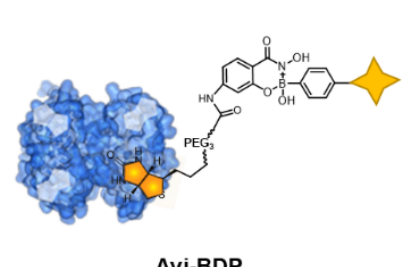

Avi-BDP

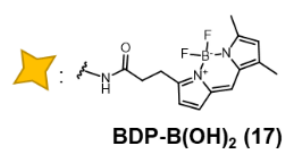

D

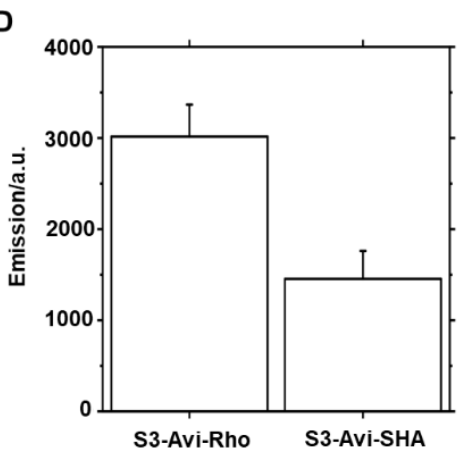

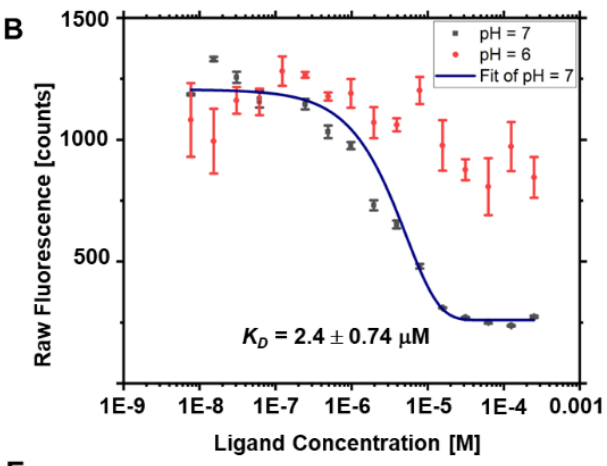

E

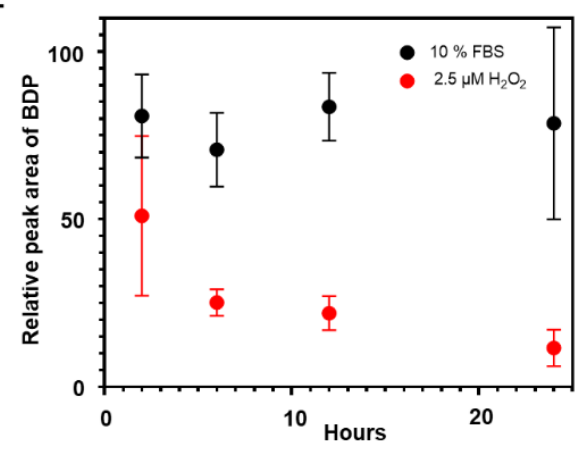

Figure 3. (A) Reaction of Avi-SHA and BDP-B(OH)2. (B) Fluorescence quenching titration of Avi-SHA against BDP-B $(\mathrm{OH})_{2}$. A $\mathrm{K}_{\mathrm{d}}$ of $2.5 \mu \mathrm{M}$ was determined at $\mathrm{pH} 7$; no binding was observed at pH 6 ( $\mathrm{n}=3$, deviation is plotted as SEM). (C) UV-VIS spectra of purified Cy5 labeled S3-AviBDP (top) and S3-Avi-Dox (bottom) complexes. (D) FRET study showing formation of S3-AviRho. (E) Stability of S3-Avi-BDP in 10\% FCS and cargo release under biologically relevant oxidative condition $\left(\mathrm{H}_{2} \mathrm{O}_{2}\right)$. 

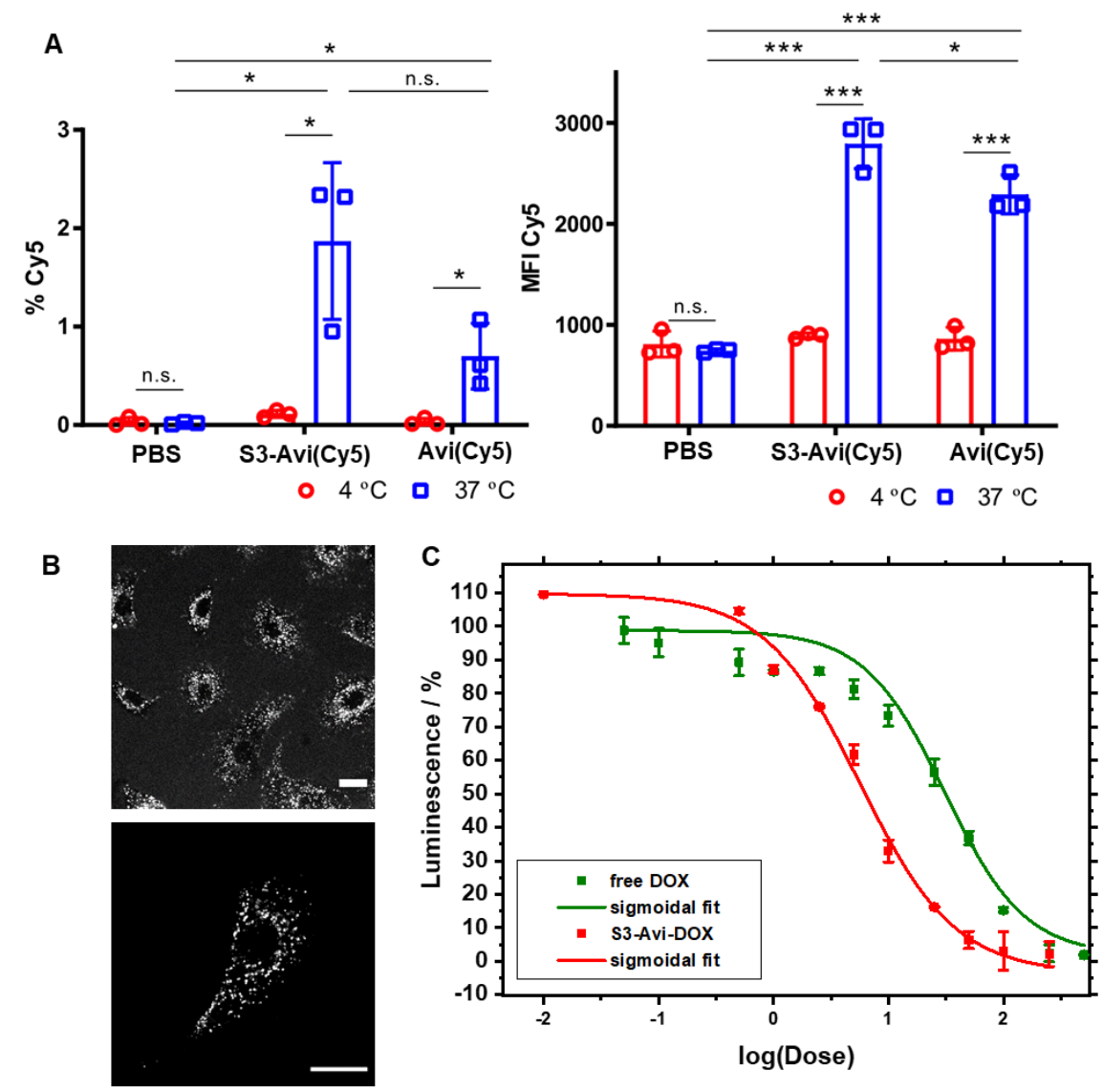

Figure 4. (A) Flow cytometry analysis of uptake of S3-Avi into A549 cells at $4{ }^{\circ} \mathrm{C}$ and $37{ }^{\circ} \mathrm{C}$ after 30 minutes incubation (n=3). (B) Cellular uptake studies of $500 \mathrm{nM}$ of S3-Avi-BDP in A549 lung cancer cells. Scale bar $=20 \mu \mathrm{M}$. (C) Cytotoxicity of free DOX versus S3-Avi-DOX in A549 cells $(n=3)$. 
A
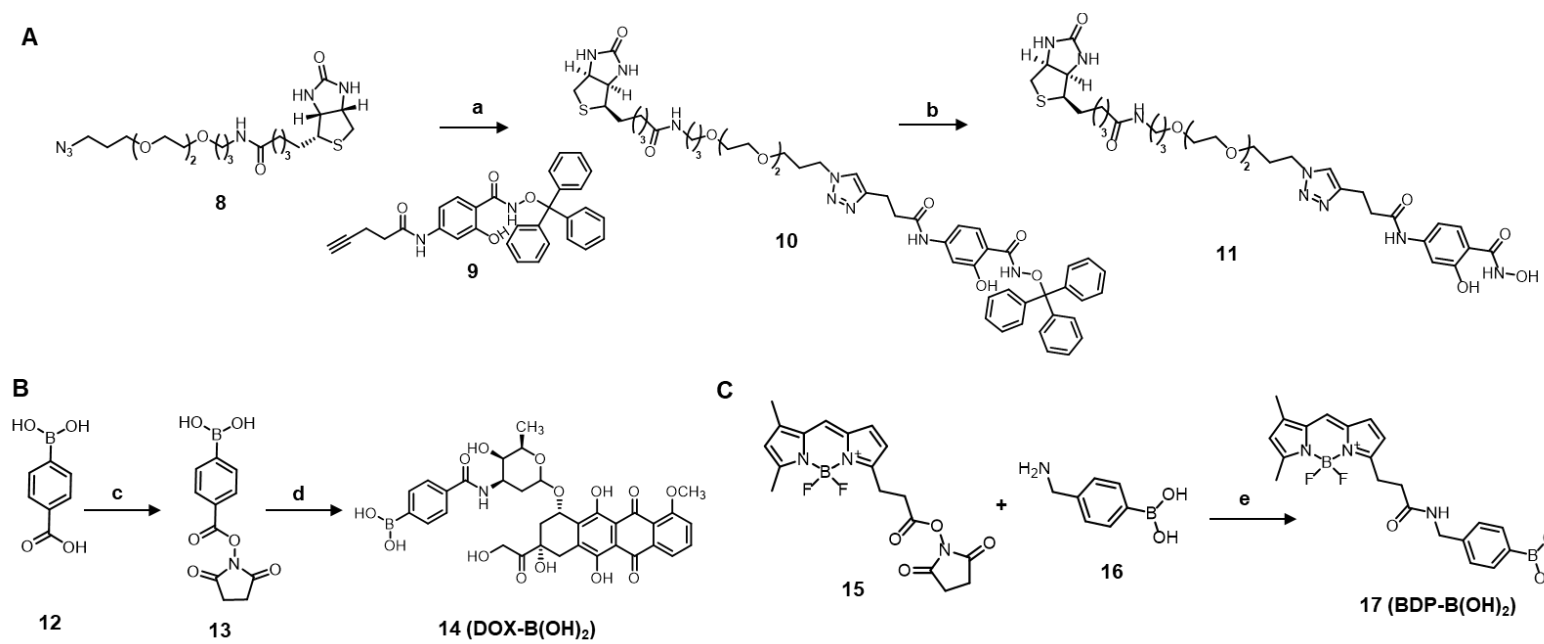

c

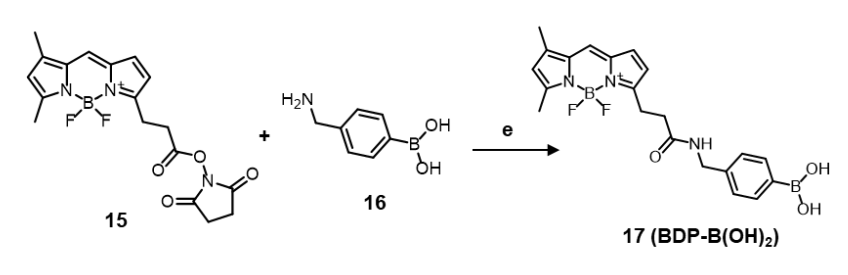

Scheme 1. (A) Two steps synthesis of biotin-SHA (compound 11) from compound 8; (a) 9, $\mathrm{CuSO}_{4}$, sodium ascorbate, tetrahydrofuran/Milli-Q, room temperature, overnight, 100\%; (b) triisopropyl silane, trifluoroacetic acid, methanol, room temperature, $2 \mathrm{~h}, 100 \%$. (B) Synthesis of DOX$\mathrm{B}(\mathrm{OH})_{2}$ (compound 14), 22\% yield; (c) NHS, EDC.HCl, DMAP, DMF, room temperature, overnight; (d) DOX*HCl, $\mathrm{NaCO}_{3}, \mathrm{ACN}, \mathrm{H}_{2} \mathrm{O}$, room temperature, overnight, $22 \%$. (C) Synthesis of BDP-B $(\mathrm{OH})_{2}$ (compound 17), 44\% yield; (e) DMF, DIEA, room temperature, overnight, $44 \%$.

Table 1. EC $_{50}$ values of conjugates with 1-3 somatostatin complexed (S1-S3) to each avidin (Avi) as demonstrated in recombinant cells (CHO-K1/Ga15/SSTR2) overexpressing SSTR2.

\begin{tabular}{l|l} 
Conjugate & $\mathrm{EC}_{50}$ \\
\hline S1-Avi & $371 \mathrm{nM}$ \\
S2-Avi & $137 \mathrm{nM}$ \\
S3-Avi & $104 \mathrm{nM}$
\end{tabular}

Supporting Information. The Supporting Information is available free of charge on the ACS Publications website at DOI: Materials, synthesis, NMR, LC-MS, western blot, cellular uptake, and cytotoxicity (PDF). 


\section{AUTHOR INFORMATION}

\section{Corresponding Author}

*Tanja Weil: weil@mpip-mainz.mpg.de

*Seah Ling Kuan: kuan@mpip-mainz.mpg.de

\section{Author Contributions}

These authors contributed equally.

\section{Notes}

The authors declare no competing financial interest.

\section{ACKNOWLEDGMENT}

The authors are grateful to the Max Planck Society and the Deutsche Forschungsgemeinschaft (DFG, German Research Foundation) - SFB 1066 (Q05, Projektnummer 213555243) for the financial support. LN acknowledges support by the DFG Emmy Noether Program (Projektnummer 417278389). We thank Dr. Matthias Arzt for the ${ }^{13} \mathrm{C}$ NMR assignment of compound 11.

\section{REFERENCES}

[1] B. Leader, Q. J. Baca, D. E. Golan, Nat. Rev. Drug Discov. 2008, 7, 21.

[2] S. Coats, M. Williams, B. Kebble, R. Dixit, L. Tseng, N.-S. Yao, D. A. Tice, J.-C. Soria, Clin. Cancer Res. 2019, 25, 5441.

[3] C. D. Spicer, B. G. Davis, Nat. Commun. 2014, 5, 740.

[4] E. A. Hoyt, P. M. S. D. Cal, B. L. Oliveira, G. J. L. Bernardes, Nat. Rev. Chem. 2019, 3, 147.

[5] J. M. Chalker, G. J. L. Bernardes, Y. A. Lin, B. G. Davis, Chem. - Asian J. 2009, 4, 630. 
[6] O. Boutureira, G. J. L. Bernardes, Chem. Rev. 2015, 115, 2174.

[7] N. Krall, F. P. Da Cruz, O. Boutureira, G. J. L. Bernardes, Nat. Chem. 2016, 8, 103.

[8] A. Dal Corso, L. Pignataro, L. Belvisi, C. Gennari, Chem. - A Eur. J. 2019, 25, 14740.

[9] J. D. Bargh, A. Isidro-Llobet, J. S. Parker, D. R. Spring, Chem. Soc. Rev. 2019, 48, 4361.

[10] S. Sindhwani, A. M. Syed, J. Ngai, B. R. Kingston, L. Maiorino, J. Rothschild, P. MacMillan, Y. Zhang, N. U. Rajesh, T. Hoang, J. L. Y. Wu, S. Wilhelm, A. Zilman, S. Gadde, A. Sulaiman, B. Ouyang, Z. Lin, L. Wang, M. Egeblad, W. C. W. Chan, Nat. Mater. 2020, 19, 566.

[11] E. Y. Jen, C.-W. Ko, J. E. Lee, P. L. Del Valle, A. Aydanian, C. Jewell, K. J. Norsworthy, D. Przepiorka, L. Nie, J. Liu, C. M. Sheth, M. Shapiro, A. T. Farrell, R. Pazdur, Clin. Cancer Res. 2018, 24, 3242.

[12] N. C. Richardson, Y. L. Kasamon, H. Chen, R. A. de Claro, J. Ye, G. M. Blumenthal, A. T. Farrell, R. Pazdur, Oncologist 2019, 24, DOI 10.1634/theoncologist.2019-0098.

[13] L. Amiri-Kordestani, G. M. Blumenthal, Q. C. Xu, L. Zhang, S. W. Tang, L. Ha, W. C. Weinberg, B. Chi, R. Candau-Chacon, P. Hughes, A. M. Russell, S. P. Miksinski, X. H. Chen, W. D. McGuinn, T. Palmby, S. J. Schrieber, Q. Liu, J. Wang, P. Song, N. Mehrotra, L. Skarupa, K. Clouse, A. Al-Hakim, R. Sridhara, A. Ibrahim, R. Justice, R. Pazdur, P. Cortazar, Clin. Cancer Res. 2014, 20, 4436.

[14] Y. N. Lamb, Drugs 2017, 77, 1603.

[15] D. Al Shaer, O. Al Musaimi, F. Albericio, B. G. de la Torre, Pharmaceuticals 2020, 13, 40.

[16] M.-R. Nejadmoghaddam, A. Minai-Tehrani, R. Ghahremanzadeh, M. Mahmoudi, R. Dinarvand, A.-H. Zarnani, Avicenna J. Med. Biotechnol. 2019, 11, 3.

[17] C. Recio, F. Maione, A. J. Iqbal, N. Mascolo, V. De Feo, Front. Pharmacol. 2017, 7, 526. 
[18] S. Muro, J. Control. Release 2012, 164, 125.

[19] S. Cao, S. Xu, H. Wang, Y. Ling, J. Dong, R. Xia, X. Sun, AAPS PharmSciTech 2019, 20, 190.

[20] S. L. Kuan, S. Fischer, S. Hafner, T. Wang, T. Syrovets, W. Liu, Y. Tokura, D. Y. W. Ng, A. Riegger, C. Förtsch, D. Jäger, T. F. E. Barth, T. Simmet, H. Barth, T. Weil, Adv. Sci. 2018, 5, 1701036.

[21] S. L. Kuan, D. Y. W. Ng, Y. Wu, C. Förtsch, H. Barth, M. Doroshenko, K. Koynov, C. Meier, T. Weil, J. Am. Chem. Soc. 2013, 135, 17254.

[22] A. J. Heck, T. Ostertag, L. Schnell, S. Fischer, B. K. Agrawalla, P. Winterwerber, E. Wirsching, M. Fauler, M. Frick, S. L. Kuan, T. Weil, H. Barth, Adv. Healthcare Mater. 2019, $8,1900665$.

[23] Z. Su, D. Xiao, F. Xie, L. Liu, Y. Wang, S. Fan, X. Zhou, S. Li, Acta Pharm. Sin. B 2021, DOI https://doi.org/10.1016/j.apsb.2021.03.042.

[24] A. Wilson, G. Gasparini, S. Matile, Chem. Soc. Rev. 2014, 43, 1948.

[25] S. J. Rowan, S. J. Cantrill, G. R. L. Cousins, J. K. M. Sanders, J. F. Stoddart, Angew. Chem. Int. Ed. 2002, 41, 898 .

[26] S. Ulrich, Acc. Chem. Res. 2019, 52, 510.

[27] J. P. M. António, R. Russo, C. P. Carvalho, P. M. S. D. Cal, P. M. P. Gois, Chem. Soc. Rev. 2019, 48, 3513.

[28] V. T. Bhat, A. M. Caniard, T. Luksch, R. Brenk, D. J. Campopiano, M. F. Greaney, Nat. Chem. 2010, 2, 490.

[29] E. T. Kool, D.-H. Park, P. Crisalli, J. Am. Chem. Soc. 2013, 135, 17663.

[30] J. Su, F. Chen, V. L. Cryns, P. B. Messersmith, J. Am. Chem. Soc. 2011, 133, 11850. 
[31] D. Y. W. Ng, M. Arzt, Y. Wu, S. L. Kuan, M. Lamla, T. Weil, Angew. Chem. Int. Ed. 2014, 53,324 .

[32] M. Hebel, A. Riegger, M. M. Zegota, G. Kizilsavas, J. Gačanin, M. Pieszka, T. Lückerath, J. A. S. Coelho, M. Wagner, P. M. P. Gois, D. Y. W. Ng, T. Weil, J. Am. Chem. Soc. 2019, $141,14026$.

[33] M. M. Zegota, T. Wang, C. Seidler, D. Y. W. Ng, S. L. Kuan, T. Weil, Bioconjugate Chem. 2018, 29, 2665.

[34] W. J. Ramsay, H. Bayley, Angew. Chem. Int. Ed. 2018, 57, 2841.

[35] N. Yang, W. Xiao, X. Song, W. Wang, X. Dong, Nano-Micro Lett. 2020, 12, 15.

[36] D. S. Wilbur, P. M. Pathare, D. K. Hamlin, S. A. Weerawarna, Bioconjug. Chem. 1997, 8, 819.

[37] T. Wang, Y. Wu, S. L. Kuan, O. Dumele, M. Lamla, D. Y. W. Ng, M. Arzt, J. Thomas, J. O. Mueller, C. Barner-Kowollik, T. Weil, Chem. Eur. J. 2015, 21, 228.

[38] T. Wang, D. Y. W. Ng, Y. Wu, J. Thomas, T. TamTran, T. Weil, Chem. Commun. 2014, $50,1116$.

[39] S. Sieste, T. Mack, C. V. Synatschke, C. Schilling, C. Meyer zu Reckendorf, L. Pendi, S. Harvey, F. S. Ruggeri, T. P. J. Knowles, C. Meier, D. Y. W. Ng, T. Weil, B. Knöll, Adv. Healthcare Mater. 2018, 7, 1701485.

[40] J. M. Lehman, M. D. Hoeksema, J. Staub, J. Qian, B. Harris, J. C. Callison, J. Miao, C. Shi, R. Eisenberg, H. Chen, S.-C. Chen, P. P. Massion, Int. J. Cancer 2019, 144, 1104.

[41] F. Barbieri, A. Bajetto, A. Pattarozzi, M. Gatti, R. Würth, S. Thellung, A. Corsaro, V. Villa, M. Nizzari, T. Florio, Int. J. Pept. 2013, 926295.

[42] S. Brocchini, S. Balan, A. Godwin, J.-W. Choi, M. Zloh, S. Shaunak, Nat. Protoc. 2006, 1, 
2241.

[43] C. Seidler, M. M. Zegota, M. Raabe, S. L. Kuan, D. Y. W. Ng, T. Weil, Chem. - Asian J. 2018, 13,3474 .

[44] M. M. Zegota, T. Wang, C. Seidler, D. Y. W. Ng, S. L. Kuan, T. Weil, Bioconjug. Chem. 2018, 29, 2665.

[45] A. K. Kenworthy, Methods 2001, 24, 289.

[46] A. G. Harris, Gut 1994, 35, S1.

[47] P. Dasgupta, R. Mukherjee, Br. J. Pharmacol. 2000, 129, 101.

[48] M. M. Zegota, M. Müller, B. Lantzberg, G. Kizilsavas, P. Moscariello, M. Martínez-Negro, S. Morsbach, M. Wagner, D. Y. W. Ng, S. L. Kuan, T. Weil, ChemRxiv 2021, This content is a preprint and has not been peer reviewed.

[49] M. Pieszka, S. Han, C. Volkmann, R. Graf, I. Lieberwirth, K. Landfester, D. Y. W. Ng, T. Weil, J. Am. Chem. Soc. 2020, 142, 15780.

[50] G. Hao, Z. P. Xu, L. Li, RSC Adv. 2018, 8, 22182.

[51] D. Pesce, Y. Wu, A. Kolbe, T. Weil, A. Herrmann, Biomaterials 2013, 34, 4360. 